\title{
El paisaje cultural almadrabero y el ejemplo de la costa de Cádiz. Aproximación desde una perspectiva patrimonialista
}

\author{
Jonatan Alcina Segura*, Santiago Amaya-Corchuelo** \\ Universidad de Cádiz (España)
}

\begin{abstract}
Resumen: El objetivo de este trabajo es doble: por un lado, analizar la figura de paisaje cultural en el contexto contemporáneo del patrimonio cultural, y por otro reflexionar sobre el caso que denominamos paisaje cultural almadrabero. El reconocimiento de bienes culturales como paisaje cultural comenzó hace veinticinco años desde UNESCO. Sin embargo, todavía hoy no existe una carta internacional sobre paisajes culturales, por lo que encontramos múltiples desacuerdos para identificarlos, analizarlos e implementar planes de gestión como los turísticos. Este artículo describe los valores del potencial paisaje cultural en la costa gaditana donde la histórica actividad pesquera almadrabera constituye una manifestación extraordinariamente significativa, incluyendo los agentes sociales vinculados a este ámbito, las acciones ya realizadas o los impactos del potencial reconocimiento sobre turismo, población local y la relación de su calidad de vida con la preservación y gestión de los valores del paisaje.
\end{abstract}

Palabras Clave: Paisaje cultural; Patrimonio cultural; Almadraba; Pesca; La Janda; Turismo.

The coast of Cádiz and the tuna traps cultural landscape: a heritage perspective.

Abstract: In this article, we analyze the present concept of cultural landscape and apply it to our coastal tuna traps fishing heritage. UNESCO has done much to give value-added to cultural landscapes but there is no international Charter that specifies how these can be identified, and managed with cultural tourism in view. This text describes the cultural values of a segment of the coast in Cádiz (Spain), where tuna trap is still practiced and its links to the quality of place and cultural identity..

Keywords: Cultural landscape; Cultural heritage; Tuna traps; La Janda; Tourism.

\section{Introducción}

La cambiante consideración sobre lo que cada sociedad y momento histórico selecciona como patrimonializable nos sitúa en un interesantísimo escenario impensable hace unas décadas. La perspectiva contemporánea sobre patrimonio cultural vincula ahora valores culturales y naturales para determinar ciertos bienes o manifestaciones que se patrimonializarán. La figura que conjuga dichos valores se denomina paisaje cultural.

En nuestro caso de análisis es necesario tener en cuenta qué agentes y en base a qué criterios deciden cuáles serán los bienes seleccionados como paisajes culturales y cuáles los excluidos. Este tipo de reflexiones ya han sido objeto de análisis (Gómez, 2010; Mateu, 2014; Zoido, 2004), en algún caso reclamando el reconocimiento de paisajes depositarios de valiosos activos patrimoniales, como el de la dehesa española y el montado portugués (Silva y Fernández, 2015). Nuestra propuesta se inscribe en dicha línea argumental, dedicándonos aquí a las particularidades del territorio comprendido entre Conil y Tarifa (Cádiz, España), donde actualmente se calan cuatro instalaciones pesqueras almadraberas de importante tradición histórica, y su potencial para ser reconocido como paisaje cultural almadrabero.

El contexto que analizamos aquí se basa en la pesca del atún rojo salvaje o atún de aletas azules -Thunnus thynnus- mediante el método conocido como almadraba, así como las labores posteriores de

* Oficina estatal para la conservación de monumentos de Baden-Württemberg; E-mail: j.alcina.s@gmail.com

** Universidad de Cádiz; E-mail: santiago.amaya@uca.es 
procesamiento de las capturas. Estos atunes realizan un movimiento migratorio anual desde el Atlántico, atravesando el Estrecho de Gibraltar, hasta los lugares de freza en el interior del mar Mediterráneo. Los atunes han sido capturados históricamente tanto en el trayecto de ida, abril-junio, como en el de retorno, julio-septiembre, calándose almadrabas de derecho y de revés. Esto ha condicionado la ubicación histórica de los enclaves almadraberos, actualmente restringida a zonas de las costas luso-española, marroquí e italiana; generándose así un paisaje sociocultural (Florido, 2017:14) resultado de la adaptación humana al ciclo migratorio mencionado.

La pesca del atún mediante este sistema se remonta a la antigüedad prerromana y lógicamente ha evolucionado a lo largo del tiempo, dando lugar a distintos tipos de almadraba, principalmente la de tiro o vista, la de monteleva y la almadraba de buche.

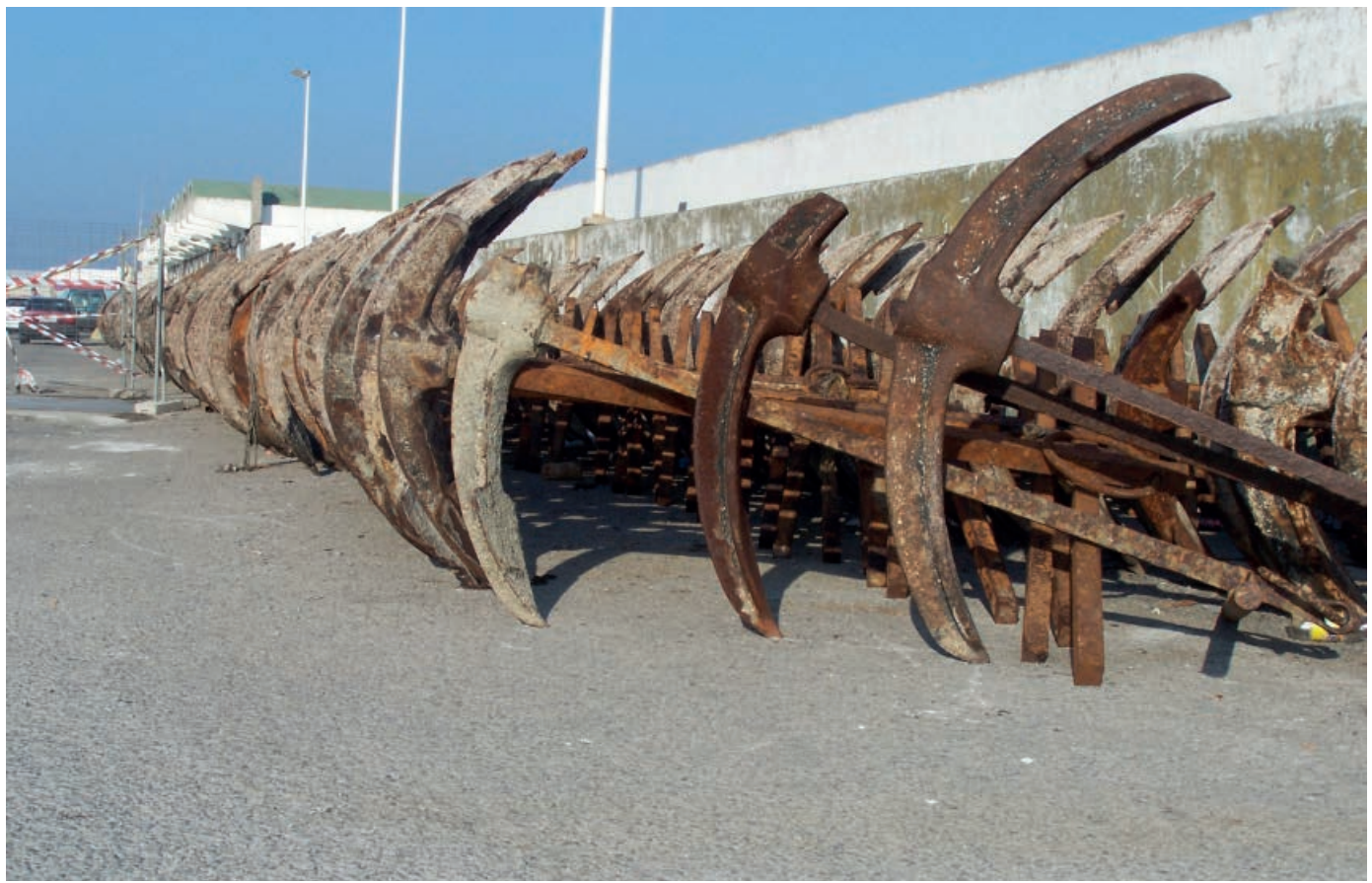

Anclas de almadraba. Fuente: Jonatan Alcina Segura

La almadraba de tiro o vista, documentada hasta el siglo XIX y ya en desuso, era un arte de pesca activo que se montaba una vez los atunes eran divisados por los torreros, que desde sus torres dirigían además la faena de las barcas que cercaban los peces con redes. Otros especialistas, los ventureros, tiraban posteriormente de las redes hasta la orilla.

La almadraba de buche es un arte de pesca pasivo conformado por un sistema de cables y redes fijas ancladas al lecho marino, en paralelo a la línea de costa, que guía a los atunes al interior, al copo. Requiere mucho menos personal para su funcionamiento que la de tiro, pero sí de una gran experiencia por parte del arráez o capitán a la hora de montar el arte, lo cual se lleva a cabo antes de la llegada del atún. Se introdujo en el suroeste atlántico en el siglo XVIII y es la que se sigue practicando actualmente. $\mathrm{Su}$ vigencia podemos vincularla, entre otras cuestiones, con una relación respetuosa con el entorno o con la necesidad de menor cantidad de mano de obra.

La almadraba de monteleva, también en desuso, era un arte de pesca pasivo de similares características a la de buche, pero de menor complejidad.

La instalación de explotaciones almadraberas ha conllevado el establecimiento de contingentes humanos que han transformado intensamente el paisaje; reflejo evidente de la singular relación hombre-recurso-adaptación, así como de las diversas coyunturas sociopolíticas bajo las que se establecieron estas pesquerías y su industria de transformación. Puede afirmarse entonces que "la industria del atún 
es factor de poblamiento en sitios costeros" (Florido, 2006) y esto se manifiesta en el legado territorial e identitario de aquellos lugares donde la pesca del atún se ha practicado secularmente. Así, el paisaje creado durante siglos a lo largo de la línea costera ubicada entre los municipios gaditanos de Conil y Tarifa, es el resultado de un intenso proceso de antropización donde la almadraba, elemento de gran «potencia civilizatoria» (Florido y Ménanteau, 2006) ha tenido un papel determinante como catalizador de procesos históricos. Se trata de un área de una enorme magnitud patrimonial donde se dan cita valores ambientales, estéticos, históricos, arquitectónicos, arqueológicos, etnológicos, industriales, etcétera.

Algunos de estos argumentos, fundamentalmente la larga tradición cultural de este tipo de pesca, ya han sido usados para solicitar el reconocimiento de las particularidades patrimoniales del territorio como veremos en las páginas siguientes. Sin embargo, queda por resolver qué tipo de reconocimiento se le otorga, en base a qué criterios y valores culturales, aplicando normas internacionales o estatales, o las consecuencias de todo ello tanto para el bien cultural como para la población local.

Por tanto, estamos ante un trabajo de profundo calado histórico, reflexivo al tiempo que propositivo en materia de patrimonio cultural. Para abordarlo empleamos una metodología que fue, por un lado, de carácter exploratoria, basada en la revisión de un abanico de fuentes secundarias. Por otro lado, realizamos charlas informales con especialistas y técnicos en las materias que aquí abordamos, antes y durante el proceso de redacción del trabajo. De esta manera podemos señalar que también aplicamos un enfoque cualitativo escasamente formal o desestructurado pero fundamental para contrastar las propuestas que formulamos en la segunda parte del trabajo. Dentro del apartado cualitativo se incluye el trabajo de campo que requirió el conocimiento directo del territorio y sus componentes culturales que aquí se tratan y sobre los que se avanzan propuestas que contienen potenciales fórmulas de carácter sociocultural, económicas y políticas.

\section{La figura de paisaje cultural a nivel internacional, estatal y andaluz}

Términos como patrimonio histórico y patrimonio cultural han sido ampliamente tratados ya desde la literatura científica (Agudo, 2003; Amaya, 2004; Aguilar y Amaya, 2007; Menasche, 2011). Estos trabajos coinciden en que se trata de un constructo social que empleado en las sociedades occidentales básicamente aplica unos cánones de valor sobre determinados bienes culturales. Las posiciones teóricas y conceptuales y la propia tutela del patrimonio cultural, así como las razones ideológicas que acompañan y promueven las tendencias en torno a lo considerado patrimonio cultural, han cambiado enormemente. En los últimos tres siglos se ha producido el salto del monumento al patrimonio cultural, llegándose a la consideración actual de patrimonializables aspectos inmateriales de determinadas culturas o incluso ámbitos territoriales singularizados por sus actividades antrópicas: "Hemos asistido del paso del patrimonio histórico, de una consideración y valoración de un bien cultural como aquel elemento excepcional, antiguo, de carácter generalmente monumental y realizado bajo los cánones y/o estilos de élites socioculturales, usado para su mera contemplación, a un concepto amplio, holístico, culturalista, integrador de parcialidades patrimoniales (arqueología, arquitectura, etnología...)" (Amaya, 2006:6). La Convención de la Haya -1954-, la Carta Europea del Patrimonio Arquitectónico -1975-, las Recomendaciones para la salvaguarda de la Cultura Tradicional y Popular-1989-, El Libro Blanco de Delors -1994- o la Cumbre Europea de Essen -1994-, por citar algunos hitos importantes, ponían ya de relieve cómo a partir de la segunda mitad del siglo XX el mundo occidental se planteó considerar el patrimonio cultural mediante una perspectiva que fuese más allá de la valoración de lo estético, histórico y monumental.

El papel de UNESCO en esta materia ha sido determinante pues en 1972 aprobó en París la Convención para la protección del Patrimonio Cultural y Natural donde abogó por la protección de bienes patrimoniales "considerando que el deterioro o la desaparición de un bien del patrimonio cultural y natural constituye un empobrecimiento nefasto del patrimonio de todos los pueblos del mundo" (UNESCO, 2006:9). En 2003 aprobó también en París la Convención para la Salvaguardia del Patrimonio Cultural Inmaterial. Estos principios emanados desde UNESCO posicionan al patrimonio cultural como un asunto de todos y le otorga un valor universal.

Este cambio de consideración sobre el patrimonio, ahora abierta e integradora, debe ser entendido en un contexto de globalización con un nuevo modelo de bienestar social, donde el incremento del sector turístico, formación, tiempo libre y el modelo público de intervención cultural, inciden directamente en la nueva valoración de bienes culturales, las acciones destinadas a su preservación-tutela y el uso que de ellos se realiza (Bendala, 2001; Carreras, 2009; Llull, 2005; Ollero, 2010). Bajo esta nueva perspectiva 
patrimonialista surgieron los precedentes de los actuales paisajes culturales, denominación con la que se le da carta de naturaleza a una nueva figura patrimonial conformada por bienes y valores culturales y naturales. La principal novedad es que reconoce la existencia de espacios y territorios cuya destacada valía patrimonial es el resultado de la combinación de valores naturales y culturales, o lo que es lo mismo, fruto de la acción del hombre sobre el territorio.

En 1972 la UNESCO utilizó la categoría de sitio o lugar para referirse a "obras conjuntas del hombre y la naturaleza así como las zonas, incluidos los lugares arqueológicos, que tengan un "valor universal excepcional" desde el punto de vista histórico, estético, etnológico o antropológico" (UNESCO, 2006:10). Este fue un paso determinante, pues de este modo el paisaje, o mejor, los valores ambientales, naturales, estéticos, espirituales, etc., presentes en el medio, pasaron a incorporarse a la esfera de lo patrimonializable junto a valores estrictamente culturales. ${ }^{1}$ No fue hasta 1992 cuando la UNESCO reconoció la categoría de paisaje cultural determinando su elección en base a su “...Valor Universal Excepcional, su representatividad de una región geocultural claramente definida y su capacidad para ilustrar los elementos culturales esenciales y distintivos de esas regiones" (2006:132). UNESCO incluyó además una clasificación de estos paisajes en tres tipos ${ }^{2}$ :

A) Paisajes claramente definidos, creados y diseñados intencionalmente por el hombre. Comprenden los jardines y parques diseñados por razones estéticas.

B) Paisajes que han evolucionado como respuesta adaptativa de un grupo cultural al medio natural. Pueden ser paisajes fósiles o bien paisajes vivos en los que las prácticas económicas tradicionales no se han estancado, ni han caído en desuso, sino que se han adaptado a los nuevos tiempos convirtiéndose en una seña de identidad cultural territorial. En estos paisajes vivos los factores culturales que los desarrollaron desempeñan un papel activo en la sociedad actual aunque muy vinculado a la tradición.

C) Paisajes culturales asociativos, con valor religioso, artístico o cultural donde las pruebas culturales materiales tienen poca o ninguna entidad.

Por otro lado, el concepto de paisaje cultural se consolidó en Florencia en el año 2000 en el Convenio Europeo del Paisaje (CEP), mediante el que se organizó la cooperación europea sobre la gestión y ordenación de los paisajes. El convenio fue ratificado por el Estado español en 2007 y sus principios se incorporaron al Plan Nacional de Paisaje Cultural (PNPC) de 2012. Este documento define qué es un paisaje cultural, cómo identificarlo y delimitarlo, y cómo orientar la selección de los mismos, señalando que la elección no recaerá en su excepcionalidad o rareza, sino por ser representativos y pertenecientes a determinado modelo de paisaje cultural; que sean ejemplos sobresalientes de territorios antropizados donde sus actividades productivas constituyan la base de la idiosincrasia física, material e inmaterial de la cultura de dicho territorio. Finalmente, el PNPC promueve el análisis de "[...] los valores culturales del paisaje en su conjunto, no sólo de aquellos considerados singulares o de interés cultural, y contextualizados en el marco de sistemas territoriales patrimoniales complejos que aportan el marco de coherencia patrimonial necesario." (PNPC, 2012: 27). Esta idea, la consideración del marco, del contexto complejo y global de carácter territorial, es también inherente a la propia figura de paisaje cultural, que promueve así la interpretación del bien cultural mediante un enfoque integral. En este marco de coherencia territorial también es imprescindible definir la escala, dimensionar adecuadamente el espacio territorial del bien cultural (municipal, supralocal, comarcal...) ${ }^{3}$.

Si bien la aplicación del PNPC es de competencia estatal, las Comunidades Autónomas (CCAA) han creado instrumentos encaminados a la catalogación, protección y valorización de sus propios paisajes culturales ${ }^{4}$. Con anterioridad a la creación del CEP y del PNPC, las CCAA habían puesto de manifiesto la importancia de sus paisajes como parte de su capital territorial.

Cabe recordar el papel de Andalucía ${ }^{5}$ en el compromiso europeo por el paisaje cuando en 1993 suscribiera junto a Toscana y Languedoc-Roussillon, la Carta del Paisaje Mediterráneo. Está claro entonces que el reconocimiento de un paisaje cultural ligado al contexto territorial almadrabero y circunscrito a un área concreta del litoral gaditano, escala supralocal, puede llevarse a cabo desde la Comunidad Autónoma de Andalucía. Para ello cuenta con instrumentos no normativos, como las figuras de protección de la LPHA (Ley de Patrimonio Histórico de Andalucía), la Estrategia de Paisaje de Andalucía (EPA, 2012) y las herramientas metodológicas desarrolladas por el Instituto Andaluz de Patrimonio Histórico (IAPH), donde destacan dos trabajos: la Guía del paisaje cultural de la Ensenada de Bolonia de 2004 y el Registro de Paisajes de Interés Cultural de Andalucía (R-PICA, 20166).

La mencionada Guía del paisaje cultural de la Ensenada de Bolonia ${ }^{7}$, fruto de la larga experiencia acumulada en el IAPH sobre el tratamiento patrimonial y holístico de los paisajes, consolida firmemente 
el concepto de paisaje cultural ligando el objeto patrimonial al contexto territorial del que forma parte. Aborda de manera multidisciplinar el ámbito de estudio, así como propone diversificar las actividades productivas y conservar los valores de la zona. Conceptualmente dicha Guía puede entenderse como el primer gran trabajo donde se recogen los lineamientos del IAPH tanto para elegir-discriminar paisajes culturales de cara a su patrimonialización, como de posibles ejes para planificar proyectos productivos basados en los valores culturales de estos paisajes.

El R-PICA, por su parte, constituye un documento orientado a sistematizar una selección de paisajes culturales andaluces. Esto supone que eleva a categoría de patrimonializados ${ }^{8}$ a los ámbitos integrantes de este registro pues le otorga carácter de reconocimiento cultural. Pero herramientas como los registros constituyen también métodos de segregación de acuerdo a determinados criterios, en este caso de valores culturales, distinguiendo a los territorios que a priori reúnen dichos valores y excluyendo a los que no. Así el PNPC señala que determinadas áreas “...han sido seleccionadas por ser depositarias de una serie de valores patrimoniales, culturales e históricos, que han participado y son testigos actuales de su formación como un paisaje cultural reconocible, significativo e identitario de Andalucía" (R-PICA, 2016:1). Desde esta perspectiva metodológica, para delimitar los paisajes culturales deben aplicarse criterios flexibles. Cuestión distinta, y no por ello necesariamente subjetiva, es si algunos contextos territoriales andaluces no incluidos en el R-PICA son también extremadamente significativos desde el punto de vista patrimonial. En este sentido, una de las destacadas exclusiones corresponde a la zona donde la actividad almadrabera ha sido una de las bases configuradoras del territorio y es hoy parte importante de su identidad, tal como señalamos antes. La afirmación no es mero atrevimiento a la luz de los datos del apartado siguiente.

\section{Valores patrimoniales del paisaje cultural almadrabero Conil-Tarifa}

La descripción de valores naturales y culturales constituye un método objetivo para comprobar la relevancia de un bien cultural y, en última instancia, determinar si es merecedor de reconocimiento legal. En este sentido, la descripción de valores patrimoniales es el argumentario de los documentos que administrativamente justifican la importancia de un bien cultural en los procesos de protección y tutela de los mismos. Los valores patrimoniales del paisaje cultural almadrabero estructuran un relato a escala supralocal, no de detalle como un monumento, ni de extensiones de ámbito comarcal o mayores; constituyen argumentos precisos sobre realidades concretas que configuran de forma inconfundible este paisaje cultural.

Aunque algunas manifestaciones culturales relacionadas con las almadrabas de nuestra área de estudio ya gozan de reconocimiento legal, son múltiples y de muy variado calado los valores que de forma inseparable constituyen esta realidad patrimonial. Diseccionamos aquí este conjunto de valores naturales y culturales para su mejor comprensión, unos de amplia profundidad histórica y evidencia material, otros más recientes y de carácter inmaterial.

Los valores naturales abarcan, en primer lugar, el marco físico; aquellos accidentes geográficos como playas, ensenadas, roquedos y ríos que conforman la franja costera contenida entre los términos de Conil y Tarifa, que por su situación en el entorno del Estrecho los convierte en lugares propicios bien para el establecimiento de pesquerías o bien de industrias de transformación, así como salinas y otras actividades auxiliares propias de estas latitudes. Algunos de elevado valor ambiental como los Monumentos Naturales del Tómbolo de Trafalgar y las Dunas de Bolonia y el Paraje Natural de la Playa de los Lances. En segundo lugar, el fenómeno biológico que cataliza el desarrollo del paisaje cultural aquí citado, las migraciones del atún.

Junto a ello, los valores culturales de carácter arqueológico e histórico nos remiten a una actividad atunera continuada a partir del período fenopúnico en este territorio gaditano. Una actividad caracterizada por la intervención "estatal" para la instalación y explotación de las pesquerías en cada periodo y asociadas históricamente a un modelo de explotación económica con vocación exportadora de salazones de atunes y otros subproductos, con una comercialización eminentemente monopolista.

Los valores arqueológicos del paisaje cultural almadrabero Conil-Tarifa nos remiten a hallazgos de época romana que testimonian un pasado atunero materializado en instalaciones fabriles. Son restos que refuerzan la afirmación de que "la Tarraconense era célebre por su vino, África por su trigo, Gades y el Estrecho de Gibraltar por su pesca y su garum [...]' (Ponsich, 1988:20) y afianzan la importancia histórica de un recurso como la pesca del atún para la antropización de este territorio gaditano; pasamos a describirlos.

En el ámbito suburbano de Conil de la Frontera se encuentra el yacimiento de El Prado, s. I d. C/ IV-V d. C., donde aparecieron, entre otros materiales, restos de ánforas Dressel 7/11, ladrillos y tejas romanas así como restos de vértebras fosilizadas de atunes que nos hablan de una más que posible factoría de salazón o cetaria junto a la desembocadura del río Salado (Ponsich, 1988:206). Según estos indicios 
ésta debió contar con su propio taller y horno de producción de ánforas, o figlina, para el transporte de las conservas así como un punto de extracción de sal.

En Barbate se hallan, entre otras infraestructuras, las piletas de la factoría romana de salazones del Cabo de Trafalgar (Amores, 1979) y en Tarifa las espectaculares ruinas de la antigua ciudad hispanorromana de Baelo Claudia, donde la manufactura del atún, así como de otras especies, fueron decisivas para la existencia del núcleo urbano y cuya "vocación marinera es mantenida en la actualidad en las almadrabas de Zahara y Conil”"(Arévalo y Bernal, 2007:24). En último lugar, también en Tarifa, los hallazgos relacionados con la ciudad de Mellaria apuntan de nuevo a la importancia salazonera en la ensenada de Valdevaqueros (Villalobos y García, 2003).

Los valores históricos de este paisaje se encuentran en referencias literarias, artísticas y documentales tales como el Archivo de la Casa Ducal de Medina Sidonia. Para los mundos fenopúnico, romano, bizantino y árabe, las fuentes ofrecen pocos datos en cuanto a la dinámica o la gestión de las almadrabas, pero sí nos confirman su fuerte presencia en el territorio, su elevada productividad y los principales ejes productivos. Por ejemplo mediante monedas como las de la ciudad de Gadir, cuyo modelo fue seguido por otras cecas del sur peninsular, en las que el atún reflejado en el reverso nos transmite la tremenda importancia de dicha actividad pesquera-comercial (Lagóstena, 2001:101). Tampoco debemos olvidar los textos que citan el trascendente papel pesquero-industrial de Cádiz y su entorno, incluida nuestra área de estudio, durante toda la antigüedad.

En época andalusí Al Mahalli, siglo XII, escribió que el atún era pescado en grandes cantidades delante de la roca conocida como Hayar al Ayyil, la Peña del Ciervo, en Tarifa (Liaño, 1997:4). También existió una almadraba entre los cabos de Roche y Trafalgar, la almadraba de Huedi Coní o del río Salado, que se ubicaría en algún punto de la costa del actual término municipal de Conil. Esto muestra que esta actividad pesquera no desapareció con la llegada de los musulmanes, de los que provienen muchos de los términos actuales de esta actividad incluyendo la palabra almadraba, sino que se mantuvo viva en el territorio.

Durante la segunda mitad del siglo XIII se produjo paulatinamente la conquista castellana del área comprendida entre la desembocadura del Guadalquivir y las costas de Tarifa. Gran parte de este territorio pasó a la jurisdicción de los Guzmán, que fueron configurando un gran señorío en la Baja Andalucía donde las pesquerías de atún jugaron un papel importantísimo en la reorganización del litoral, especialmente en el área que aquí estudiamos, y supusieron además una de las actividades económicas más importantes de este linaje.

En la Edad Moderna los Guzmán, ya duques de Medina Sidonia, conformaron además un auténtico señorío almadrabero en el que destacan las productivas almadrabas de Conil y Zahara, en cuyos orígenes están también el de estas poblaciones. Por su cercanía a Berbería y por el atractivo contingente humano que ofrecían al corso berberisco los trabajadores de las almadrabas, las costas de Conil a Tarifa se convirtieron en foco habitual de ataques (Aragón, 2009: 164). La protección y vigilancia del litoral pasó a ser cuestión de interés general y por este motivo las infraestructuras de algunas de estas pesquerías desempeñaron la doble función pesquera y defensiva. Las almadrabas se convirtieron en un fenómeno social que llamó la atención de Miguel de Cervantes -La Ilustre Fregona- y quedaron reflejadas en el trabajo de los artistas flamencos Hoefnagel y Van den Wyngaerde. Estas recreaciones literarias y artísticas contribuyeron a establecer y difundir una temprana imagen del paisaje cultural que proponemos.

La decadencia propia de las almadrabas suratlánticas entre finales del siglo XVII y el primer tercio del siglo XVIII deja entrever la escasa rentabilidad de la costosa almadraba de tiro en tiempos de crisis. Esto abrió la puerta a la introducción del arte de buche en el suroeste andaluz, que arrinconó al arte de tiro hasta su desaparición definitiva en el último tercio del siglo XIX.

La etapa monopolística protagonizada por los Guzmán se vio frenada por la liberalización del sector iniciado en las Cortes de Cádiz, que declaró abolidos los señoríos y los privilegios de pesca en 1811, y definitivamente en 1817. Así durante el siglo XIX surgieron almadrabas nuevas a lo largo de la costa gaditana, algunas de breve duración. Entre 1875 y 1928 asistimos a la liberalización plena del sector, al desarrollo técnico de los procesos de pesca, así como de su industria, con la consiguiente proletarización de los trabajadores -colonias industriales, y a la expansión de su mercado (Florido, 2017: 69-71).

De 1928 a 1971 fue la época del Consorcio Nacional Almadrabero (CNA). Éste unía a un grupo de concesionarios, constituidos bajo el Sindicato Nacional Almadrabero y al Estado, lo que supuso la recuperación y ampliación del sistema monopolístico de explotación. El proceso industrializador conllevó un modelo de poblamiento distinto al anterior, los poblados-factoría. La concentración productiva permitió la reproducción de otra de las características seculares de la almadraba, el impulso de migraciones interiores peninsulares de fuerza de trabajo. Si bien la liquidación definitiva del Consorcio se produjo en 1973, ya en 1972 las almadrabas se adjudicaban mediante subasta pública, y recayeron de nuevo en 
mano de unas pocas familias (Crespo, Carranza, Ródenas y Ramírez), algunos accionistas del Consorcio, que asumieron las inversiones necesarias para su explotación, como así continúa hoy con escasos cambios.

Durante los años 80 el modelo productivo se había transformado debido a la aparición de agentes comercializadores japoneses que adquirían la mayor parte de las capturas de atún rojo. Son empresas que disponían de barcos con cámaras de ultracongelación $\left(-60^{\circ} \mathrm{C}\right)$ en los que se desembarca directamente el atún desde los barcos de la almadraba. Sin dejar de ser el mercado japonés el principal cliente, ya a partir de los 90 los atunes han pasado a ser distribuidos desde instalaciones de ultracongelación en tierra ubicadas en Barbate que favorecen a su vez la venta del atún en el mercado local y regional.

Entre los valores de carácter arquitectónico hay que señalar hitos como las torres de Castilnovo y Torre del Puerco, ambas en Conil, la Chanca de Zahara o el castillo medieval de Conil, BIC desde 1985, construcciones con una doble funcionalidad defensiva a la vez que productiva. Destaca sobremanera la conservación de la histórica chanca de Conil, hoy Lugar de Interés Etnológico, construida en el siglo XVI y dedicada al despiece y salazón del atún de la almadraba, a almacenar las artes, barcas y material de pesca. Permanece también en pie la chanca levantada en Barbate por el CNA en torno a cuyo patio se establecieron no solo las dependencias dedicadas al trabajo sino las habitacionales, algunas aún en uso, encaminadas a alojar la mano de obra procedente de otros puntos de la geografía, sobre todo de la provincia de Huelva.

También debemos aludir a los procesos de transformación urbanísticos y territoriales directamente relacionados con fenómenos de evergetismo y maniobras políticas por parte de los magnates del atún. Así el casco urbano barbateño fue consolidándose mediante las acciones llevadas a cabo por el empresario atunero Serafín Romeu Fagés, Conde de Barbate. Éste gestionó la creación del puerto pesquero de Barbate y costeó pavimentado, acceso al agua potable y alcantarillado de la zona industrial, así como la construcción de la aduana antigua, del Colegio de Nuestra Señora del Carmen de Barbate, la primera escuela en la población de Zahara de los Atunes y realizó una sustanciosa donación para la construcción de la antigua iglesia del Carmen y San Paulino (Conde, 2007; Florido, 2017:76).

Barbate y el barrio de Zahara de los Atunes se segregaron de Vejer de la Frontera el 11 de marzo de 1938. Este hecho fue promovido por los propios empresarios almadraberos y armadores de la zona justificándose "sobre la falta de correspondencia entre las aspiraciones e identidad de ambos pueblos, pesquero e innovador uno, agrícola, ganadero y tradicional, el otro" (Rivas y Frende, 2003:108). De este modo acaba reconociéndose en la propia ordenación del territorio la indiscutible vocación marítima y pesquera barbateña con respecto a la tradición agrícola del municipio de Vejer.

Los valores etnológicos de este paisaje cultural almadrabero nos remiten a la forma de vida de los habitantes de este territorio, concretamente a las relacionadas con la pesca del atún. Abarcan los sistemas de gestión y explotación de la materia prima, los procesos tecnoeconómicos de producción y saberes técnicos asociados -en este sistema de pesca tanto los saberes técnicos más especializados como los derechos de participar laboralmente en la almadraba se han transmitido secularmente de padres a hijos-, el lenguaje pesquero, los rituales asociados a ello o las prácticas culinarias, entre otras muchas.

La almadraba es un sistema de pesca que exige una gran capacidad económica y de organización para desarrollarla. Esto ha condicionado los sistemas de explotación, que son, en última instancia, los que han determinado la expansión, el retraimiento y/o la permanencia de este tipo de industria en el territorio hasta llegar a la actualidad. Dichos sistemas han sido fundamentalmente de dos tipos, por un lado monopolísticos, bajo el señorío de los Guzmán y el CNA, y por otro de cierta apertura, tras la liberalización del sector con las Cortes de Cádiz en 1811 y en la actualidad.

La industrialización más intensiva de la producción almadrabera en el último tercio del siglo XIX tuvo una fuerte repercusión territorial como mencionamos antes. Los trabajadores de esta época procedentes de otras localidades, vivían en barracas y caseríos construidos por los empresarios. En caso de afluencia masiva de trabajadores, surgían enormes asentamientos de autoconstrucción de los trabajadores de almadrabas u otras pesquerías ocasionales. A partir de la instauración del Consorcio, los empresarios, bien construyeron nuevos poblados-factoría, bien modernizaron viejos enclaves pesqueros. El aumento de mano de obra en época del CNA hay que relacionarlo con una fuerte actividad en torno a las conservas y grandes centros fabriles.

Constituye un destacable valor etnológico el propio sistema técnico de captura de los atunes, las ya citadas almadrabas de tiro, de monteleva, y de buche, que es la que se practica aún, y en la que participan profesionales que desempeñan labores de capitán, administrador de mar, patrón, proel, copejeador, marinero, motorista, velamen, buceadores, etc.

Otros valores de carácter simbólico e inmaterial, pero muy significativos, tienen que ver con el uso de la pesca y/o los atunes como emblema local: los escudos de Conil de la Frontera, Barbate y Zahara de los Atunes. En todos se hace referencia directa a la pesca del atún como su origen y una de sus señas de identidad más representativas. Como nos recuerda la Ley 6/2003, de 9 de octubre, de símbolos, tratamientos y registro 
de las Entidades Locales de Andalucía: "[...] el valor de los distintos símbolos como representativos de las agrupaciones o colectividades no depende ya tanto de su ortodoxia heráldica, cuanto de su identificación por la población de la Entidad Local, siendo este respaldo popular el que eleva el símbolo a la categoría de representativo de la misma [...]". Si bien en el caso de Tarifa, pese a la importancia de sus pesquerías, el escudo hace solo referencia a su papel como punto fuerte de control del paso del Estrecho.

\section{Escudo Conil de la Fra.}

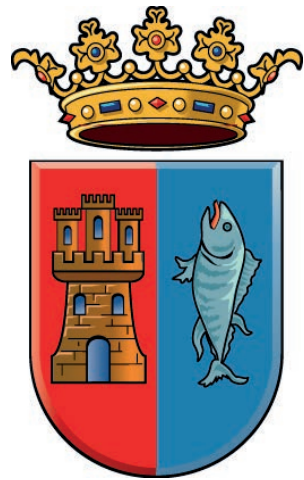

Escudo de Barbate
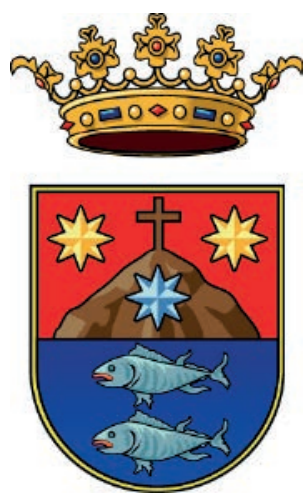

Escudo de Zahara de los Atunes

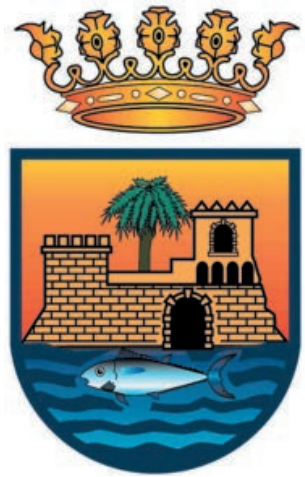

Fuente: Fuentes: Web Diputación de Cádiz y web E.L.A de Zahara de los Atunes

Los topónimos, valores en la línea de los recién expuestos, también expresan simbólicamente procesos de conformación del paisaje cultural puesto que estos ubican a los lugares en una realidad concreta expresando relaciones de pertenencia. Este fenómeno alcanza su máxima expresión en Zahara de los Atunes, Entidad Local Autónoma de Barbate por el Decreto 2014/2011, de 14 de junio, cuyas almadrabas han sido históricamente consideradas de las más importantes en número de capturas, "motivo por el cual este pueblo lleva el nombre de Zahara de los Atunes" (Ponsich, 1988:27).

Identificación colectiva, símbolo e identidad histórica y actual, autorrepresentación como grupo humano, constituyen valores inherentes a la situación descrita; son poderosos valores de referencia que coadyuvan decisivamente para conformar este paisaje cultural como almadrabero. Así llegamos a la actualidad, a las sociedades herederas de milenios de constructo del territorio en el que habitan, y uno de sus ejes ha sido la pesca del atún mediante las almadrabas y su posterior transformación y consumo. Hoy tradición e innovación se dan la mano en una realidad viva y cambiante, muy dinámica tal como demuestran la cantidad y variedad de actividades cuya centralidad continúa siendo la pesca atunera de almadraba.

Encontramos valores etnológicos como la verdadera agitación culinaria que existe respecto al atún rojo de almadraba como producto alimentario. La alimentación como actividad consustancial a cada cultura y territorio muestra en el caso del atún rojo una vitalidad inusitada. Ya no se basa en las recetas y cortes tradicionales del atún, bien en fresco o en conservas, lo cual sigue generando valor etnológico ${ }^{9}$, sino en las innovaciones aplicadas, en las tipologías de cortes o en los niveles de diversificación culinaria que se están alcanzando utilizando el atún como ingrediente básico. Todo ello ha dado pie a la popularización del ronqueo ${ }^{10} \mathrm{y}$ a elevar a producto gourmet al atún rojo. Íntimamente asociado a ello han surgido intensos reclamos para los visitantes y turistas, tales como la Ruta del Atún, fiesta gastronómica celebrada en Conil, Barbate, Zahara y Tarifa que en 2018 alcanzará respectivamente su vigesimosegunda, undécima, décima y sexta edición.

En conclusión, a la enorme panoplia de valores históricos, arqueológicos, arquitectónicos, industriales, etnológicos, artísticos, etc., actualmente se añaden otros valores contemporáneos que complementan a los señalados y que se sustancian en museos, rutas turísticas, eventos culinarios, rituales festivos, saberes y especializaciones técnicas sobre el mar y la pesca, el habla marinera ${ }^{11}$ o el propio turismo concebido como actividad productiva de enorme impacto. Son prácticas sociales sobre las que se basa la identidad cultural de este territorio en el presente y que, en gran parte, siguen centrándose en la pesca, el atún y las almadrabas, en su cultura marina, marinera y pesquera.

Los valores culturales inherentes a este territorio almadrabero, si bien ponen de manifiesto la relevancia patrimonial del caso y su posible valor universal excepcional, nos generan una serie de dudas 
que contribuyen a su análisis desde una perspectiva patrimonial, dando respuesta así a uno de nuestros objetivos. ¿Cómo definir y delimitar este caso de paisaje cultural?, ¿en base a lo descrito se justifica su inclusión en un registro de carácter regional como el RPICA?, ¿debe ser una entidad internacional como UNESCO la que incluya este caso en la Lista del Patrimonio Mundial?, ¿quizás estos valores culturales, muchos vivos y dinámicos e inmateriales, constituyen un impedimento para el reconocimiento administrativo del paisaje cultural almadrabero?, ¿qué actores sociales se han implicado ya en ello?, ¿qué efectos tendría la inscripción de este paisaje cultural en el ámbito de las políticas culturales estatales e internacionales?, ¿cómo se estructurará la dimensión comercial y turística, inherente a estos elementos una vez patrimonializados en la liberal lógica mercantil dominante del consumo cultural?, ¿en qué modo el reconocimiento de este nuevo ámbito patrimonial influirá sobre el propio "bien cultural"?.

\section{Discusión sobre el reconocimiento del paisaje cultural almadrabero}

El paisaje cultural almadrabero propuesto en este artículo se define como un territorio creado por el hombre en unas condiciones históricas concretas en las que la pesca del atún va a ser el elemento clave en el proceso de territorialización así como un motor de transmisión de valores culturales con la peculiaridad de que este tipo de pesca, pese a intervalos, sigue aún practicándose en la zona y mantiene su papel como elemento catalizador de los ámbitos socioculturales y económicos de las sociedades que la habitan. Es un concepto amplio en el cual se incluyen todos aquellos lugares, actividades, manifestaciones, muebles e inmuebles vinculadas a la pesca del atún rojo mediante este sistema de redes en alguna de sus variantes y a su conversión en producto de consumo.

Por eso hemos escogido como paradigma la franja costera continua formada por los municipios que discurren entre el litoral de la Janda y la vertiente atlántica del Campo de Gibraltar: Conil de la Frontera, Barbate, Entidad Local Autónoma de Zahara de los Atunes y Tarifa. Así mismo incluimos la costa de Vejer de la Frontera, de donde se desgajaron a lo largo de la historia Conil y Barbate y a los que sirve de nexo. Para el reconocimiento administrativo de este paisaje, en sintonía con las recomendaciones internacionales al respecto, hay que señalar la importancia de los valores culturales antes descritos y la identificación de las poblaciones de este territorio con dicha actividad pesquera ${ }^{12}$. Por tanto, estamos afirmando que la cosmovisión de los ciudadanos y la importancia de las agencias sociales ancladas al territorio (Carrera, 2015) constituyen variables determinantes ante posibles actuaciones administrativas.

\section{Plano de la propuesta de delimitación del paisaje cultural almadrabero}

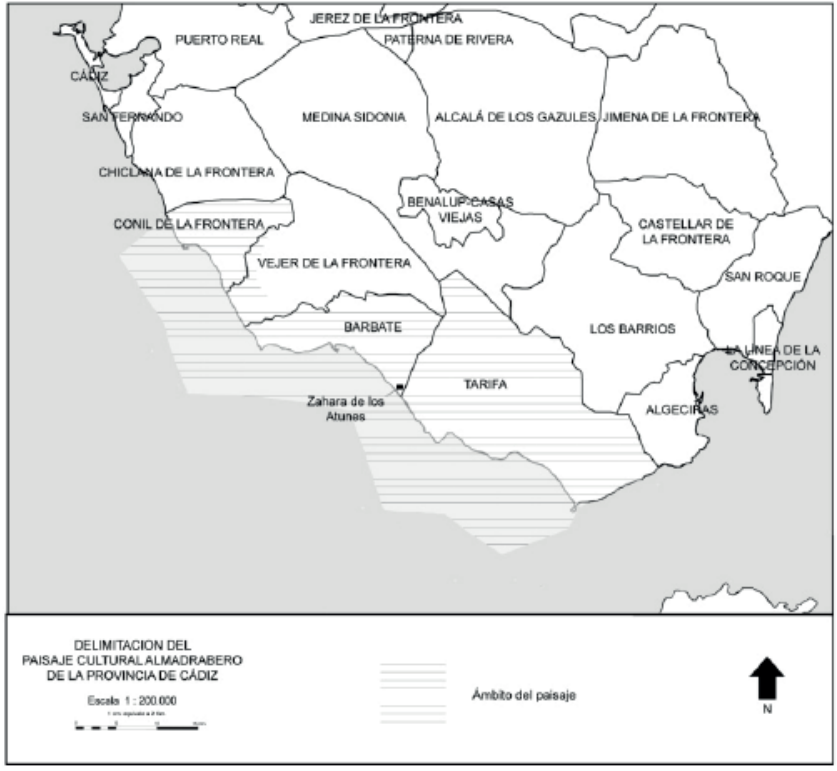

Fuente: elaboración propia 
A lo largo del golfo ibero-marroquí y el mar Mediterráneo existen testimonios de pesquerías almadraberas, y como en la costa gaditana algunas siguen aún calándose. En consecuencia existen paisajes almadraberos fósiles y otros vivos, actuales, muy dinámicos material y simbólicamente. El registro de almadrabas autorizadas de 2018 según la Comisión Internacional para la Conservación del Atún Atlántico (ICCAT) ${ }^{13}$, constituye un registro de partida. Recoge veintinueve pesquerías repartidas del siguiente modo: cinco almadrabas en España (Conil, Barbate, Zahara, Tarifa y La Azohía), seis tonnara en Italia (Liguria, Sicilia y Cerdeña), quince madarib en Marruecos (Larache, Tánger y mar de Alborán) y tres armaçoes en Portugal (Tavira y Faro). Esto hace aplicable nuestro modelo de paisaje cultural a otras entidades territoriales fuera del ámbito andaluz y su reconocimiento puede ser abordado desde instancias regionales o estatales, o bien conjuntamente desde otras de carácter internacional. La delimitación del paisaje cultural almadrabero gaditano podría ser considerada por el R-PICA o por el Atlas, también para declararlo BIC. Para una posterior inclusión en la Lista Tentativa PM debería ampliarse el foco. Entonces, si el proceso se afronta de forma global, se tomarían en cuenta las almadrabas gaditanas así como otras relevantes del entorno atlántico-mediterráneo.

La relevancia y el peso específico en términos culturales derivados de la continuidad histórica del fenómeno almadrabero en estos territorios los convierte a todos en potenciales paisajes culturales almadraberos ¿Cabría entonces una declaración conjunta de $\mathrm{UNESCO}^{14}$ que incluya todos los territorios donde la actividad es significativa?, ¿son los estados los que, dependiendo de sus políticas de tutela, centrales o regionales, decidan cuáles de estos enclaves concuerdan con el concepto de paisaje cultural y actúen en consecuencia?.

Ahora bien, en el caso de las almadrabas gaditanas nuestros argumentos ya han sido objeto de demanda por algunos agentes sociales. Tenemos varios precedentes claros, como el Grupo de Desarrollo Pesquero Cádiz-Estrecho creado en 2009 en Barbate, que promueve la gestión y ejecución de proyectos relacionados con la pesca ${ }^{15}$. En 2010, como ya mencionamos, iniciaron la solicitud para la declaración de las cuatro almadrabas gaditanas en funcionamiento como Bien de Interés Cultural. Otro agente importante es la Federación Andaluza de Cofradías de Pescadores, que en 2010 publicó la obra Almadrabas del Estrecho y Literatura, donde refuerza la vinculación de estas poblaciones costeras y su cosmovisión con la pesca del atún. También hemos de tener en cuenta la labor de la Organización de Productores Pesqueros Almadraba (OPP-51), implicado en actividades de difusión y puesta en valor de los aspectos naturales y culturales del paisaje aquí propuesto, como la creación del Centro de Interpretación del Atún de Almadraba, en Barbate, o una ruta a bordo del Francisco Varo, un antiguo barco almadrabero ${ }^{16}$.

La intervención de distintos agentes sociales en los procesos de patrimonialización es un tema apasionante y generador de tensiones, relaciones de poder asimétricas y conflictos (Amaya y Aguilar, 2014). Dichos actores, desde los institucionalizados del propio territorio como hemos señalado, los administrativamente competentes y otros muy variados como académicos o políticos, sociedad civil, asociaciones, etcétera, ocupan un lugar asimétrico en una compleja red donde cada uno de ellos intenta apropiarse del universo simbólico característico de los procesos históricos afines al bien cultural en cuestión, aspirando en muchos casos a monopolizar su uso exclusivo. Este hecho, que puede sustanciarse comercialmente de distintos modos, marcas de calidad alimentaria o de algún otro tipo, les reportará importantísimos beneficios, materiales y/o inmateriales, si consiguen ostentar hegemónicamente determinado símbolo, palabra o sello, tal que atún, atún de almadraba, etcétera.

Estas ideas nos ubican ya en el apartado de posibles efectos de reconocer patrimonialmente al paisaje cultural almadrabero. Nos sitúan ante el omnipresente mercado y las políticas culturales neoliberales ${ }^{17}$ que utiliza el márquetin para influir de forma determinante en estas dinámicas que redefinen los referentes culturales asociados a territorios y grupos sociales concretos para incorporarlos en forma de productos y comercializarlos globalmente con nuevos sentidos (Lozano y Aguilar, 2010). Lógicas socioeconómicas y culturales pesqueras y marineras locales, incorporadas a modelos económicos, capitalizados y globalizados; actores sociales que promueven determinada idea de la historicidad y legitimidad cultural de la geografía de origen y reafirman la idea sobre la autenticidad. Atún rojo de almadraba es un término popular que sustancia y evoca la historicidad y autenticidad cultural de un territorio, un sello sociocultural de tremenda potencia comercial y turística que repercute claramente en su valor añadido. A esto habría que sumar la creación de la marca comercial Atún Salvaje de Almadraba del Sur de España.

Realmente estamos en un espacio turístico en el que el atún se presenta como la faceta material del discurso histórico de estos municipios a lo largo de los siglos, municipios, no lo olvidemos, inmersos en un proceso de reconversión turístico-cultural en el que la "playa", en todas sus posibilidades, se complementa con multitud de ofertas derivadas del atún y la pesca en sus costas: culinarias, paisajísticas, museísticas, etcétera. 
La propia dinámica sociocultural de esta realidad almadrabera, como señalamos ya, crea nuevos valores culturales, vivos y contemporáneos. Esto nos posiciona ante la más que razonable duda de si quizás estos valores culturales coetáneos, vivos y dinámicos, mayoritariamente inmateriales, constituyen un impedimento para el reconocimiento del paisaje cultural almadrabero. Si una sociedad posee hondos referentes históricos, los actualiza, los dinamiza, los diversifica de forma que consigue vivir de ellos, estamos ante la creación de nuevos valores culturales. Es una idea que nos incardina claramente con los lineamientos actuales sobre patrimonio cultural, concepto holístico e integrador. Sin embargo, parte de aquellos actores sociales que hemos mencionado antes, particularmente los que deciden qué casos sean merecedores del marchamo "paisaje cultural", puedan ver un impedimento en el dinamismo socioeconómico y cultural que muestran las almadrabas. Es un hecho paradójico pero muy extendido. Los valores patrimoniales vivos, dinámicos, actuales, no meramente históricos de valor fundamentalmente estético y monumental, y sobre todo de naturaleza inmaterial, siguen siendo un problema para su reconocimiento, su declaración y la posible protección de los mismos.

Es innegable el aumento de registros de prácticas cuyos valores culturales predominantes son inmateriales -en el ámbito alimentario, prácticas y rituales festivos, etcétera- o que la salvaguardia del patrimonio cultural inmaterial goza de muy buena acogida, lo cual proporciona al patrimonio inmaterial una legitimidad que no tenía antes de ser introducido en la escala internacional (Bortolotto, 2017). Otra cuestión muy diferente es la formación y convicción sobre los valores culturales inmateriales de los agentes que deciden en marcos estatales o autonómicos qué se reconoce y qué no como patrimonio.

Estamos asistiendo a otra de las grandes paradojas del patrimonio y del paisaje cultural almadrabero. En múltiples ocasiones solo hay que revisar las inscripciones y declaraciones de BIC en BOE y BOJA, se siguen seleccionando como patrimonializables bienes en riesgo de desaparición, con valores culturales cuya vigencia sociocultural se extinguió o bien no son representativos para las poblaciones donde se ubican, pero que constituyen, en definitiva, el estereotipo de lo patrimonial presente y de aplicación en muchos casos: material, artístico, escaso, histórico, estético... Y el caso de las almadrabas gaditanas requiere de una perspectiva en sintonía con los criterios de UNESCO o el mismo R-PICA para afrontarlo, patrimonialmente abierto, integrador y holístico, además del ingrediente determinante que hasta ahora no ha hecho su aparición en esta escena, la voluntad política.

\section{Conclusiones}

El paisaje cultural almadrabero constituye un territorio en el que se incluyen lugares, actividades, manifestaciones, muebles e inmuebles, materiales e inmateriales vinculados a la pesca del atún rojo y a su industria, donde siguen calándose almadrabas y donde dicha actividad es una de las bases de sus señas de identidad. En nuestro caso de estudio su delimitación geográfica es una franja costera perteneciente a la provincia de Cádiz, que abarca el litoral jandeño y la vertiente atlántica del Campo de Gibraltar. Por tanto, el paisaje cultural almadrabero que proponemos es un área bien definida y delimitada.

En absoluta sintonía con otros paisajes culturales ya reconocidos desde UNESCO o los incluidos en el R-PICA, hemos señalado que esta situación reúne sobradamente abundantes valores culturales de una cultura marina, pesquera y almadrabera susceptibles de ser patrimonializados mediante dicha figura. Desde los propios restos materiales y su impronta en el territorio, los procesos y relaciones de producción, distribución y consumo del atún, los oficios, actividades y conocimientos vinculados a esta actividad, hasta los valores, digamos emergentes, la realidad es incuestionable. Ahora bien, es necesario insistir en la idea de que el reconocimiento patrimonial de este paisaje cultural carecería de sentido si no se incardina en un proyecto de mayor alcance que estabilice la insegura actividad pesquera actual, garantizando su mantenimiento y sostenibilidad. Realmente el alcance de la inclusión de este caso en un listado sólo supone un gesto de lo que debe constituir un verdadero proyecto de amplio calado sociopolítico.

Además para evitar aquellos efectos desfavorables sobre la realidad cultural mediante la conversión de la cultura en mera mercancía, el desarrollo económico asociado a una inscripción como paisaje cultural es recomendable que vaya directamente asociado a la divulgación y concienciación de la población local como una fórmula de evitar la descontextualización y la pérdida del marco de referencia del sentido cultural de este caso. La formación reglada en los colegios, por ejemplo, es una excelente fórmula para ello y ya se empieza a aplicar. 
Si bien nuestra reflexión y análisis en este trabajo están dedicados al paisaje cultural almadrabero, creemos firmemente en que su reconocimiento debería formar parte de una estrategia patrimonializadora y decididamente política de amplio alcance, en la que, más allá de aplicar modelos ultraliberales de políticas culturales al uso, abogue por un proyecto que incluya investigación, difusión, conservación, salvaguardia, etc., del mismo modo que el reconocimiento expreso hacia las poblaciones locales donde se lleva a cabo la actividad almadrabera hasta hoy, protagonistas de este complejo cultural.

\section{Bibliografía}

Agudo Torrico, J.

2003. "Patrimonio y derechos colectivos". En Quintero, V. y Hernández, E. (Coords.), Antropología y patrimonio: investigación, documentación e intervención (pp. 12-29). Granada: Junta de Andalucía. Aguilar Criado, E. y Amaya Corchuelo, S.

2007. "El patrimonio cultural como activo de desarrollo rural". En Sanz, J. (Ed.), El futuro del mundo rural (pp. 103-124). Madrid: Editorial Síntesis.

Alcina Segura, J.

2016. La provincia de Cádiz en un cuaderno. Cádiz: Ed. Q-Book.

Alcina Segura, J.

2018. "La almadrabera española. Una industria importantísima que San Fernando desconoce". Disponible en: http://www.patrimoniolaisla.com/la-almadrabera-espanola-una-industria-importantisima-san-fernando-desconoce/ (consultado 3.3.2018)

Álvarez Muñarriz, L.

2011. "La categoría de paisaje cultural". Revista de Antropología Iberoamericana, 6 (1): 57-80.

Amaya Corchuelo, S.

2004. "Los usos de los bienes culturales según los criterios actuales sobre el patrimonio cultural.

Evolución histórica. El caso de Extremadura". Piedras con Raíces, 6: 4-9.

Amaya Corchuelo, S. y Aguilar Criado, E.

2014. "Actores sociales en conflicto. Procesos de patrimonialización del jamón ibérico". En Periferias, fronteras y diálogos. Actas del XIII Congreso de Antropología de la Federación de Asociaciones de Antropología del Estado Español (pp. 5366-5393). Tarragona: Ed. Universitat Rovira i Virgili,

Amores Carredano, F.

1979. "Una nueva factoría de salazones en Trafalgar". Habis, 9: 441-453.

Aragón Fernández, A.

2009. Asalto de piratas berberiscos al litoral de la Janda. Tarifa: (s.e).

Arévalo González, A. y Bernal Casasola, D.

2007. Las Cetariae de Baelo Claudia. Avance de las investigaciones arqueológicas en el barrio meridional (2000-2004). Sevilla: Ed. Consejería de Cultura Junta de Andalucía y Servicio de Publicaciones de la Universidad de Cádiz.

Azorín.

1940. El paisaje de España visto por los españoles. Madrid: Espasa-Calpe, S.A.

Bendala Galán, M.

2001. "Los conjuntos arqueológicos y sus contextos ante las exigencias de los nuevos tiempos". En Actas de los XI Cursos Monográficos sobre el Patrimonio Histórico (Reinosa, julio 2000) (pp. 237-254). Reinosa: Universidad de Cantabria, Ayuntamiento de Reinosa.

Bernal Casasola, D.

2016. "Conil en la Antigüedad Clásica. Entre Mercablum, el garum y el retrotierra agropecuario". En Ramos Muñoz, J.; Cantillo Duarte, J.J; Vijande Vila, E. (Coords.): Las sociedades prehistóricas y la arqueología de Conil en el contexto de la banda atlántica de Cádiz (pp. 217-240). Conil: Ediciones Pinsapar (Ancestros).

Bortolotto, Ch.

2017. "Como comerse un patrimonio: construir bienes inmateriales agroalimentarios entre directivas técnicas y empresariado patrimonial”. Revista andaluza de antropología, 12: 144-146.

Carrera Díaz, G.

2015. Propuesta metodológica para la documentación y gestión del patrimonio cultural inmaterial como estrategia de desarrollo social y territorial. Tesis doctoral. Universidad de Sevilla. Disponible en: https://idus.us.es/xmlui/handle/11441/34477(consultada 6.4.2018) 
Carreras Monfort, C. (Coord.)

2009. Evaluación TIC en el Patrimonio Cultural: metodologias y estudio de casos. Barcelona: Universitat

Oberta de Catalunya.

Comisión Nacional Española de Cooperación con la UNESCO

1981. Convenciones, recomendaciones y declaraciones de la UNESCO. Madrid.

Contreras Hernández, J.

2005. "Patrimônio e globalização: o caso das culturas alimentares". En Canesqui, A. M. e García, R. W.

D. (org.) Antropologia e Nutrição: um diálogo possível. Rio de Janeiro: Fiocruz.

Florido del Corral, D.

2006. "Las almadrabas andaluzas: entre el prestigio y el mercado". En Chic, G. (Dir.) Las Almadrabas Andaluzas: Entre el Prestigio y el Mercado. Economía de Prestigio Versus Economía de Mercado, 1, (pp. 193-214). Sevilla: Padilla Libros Editores y Libreros.

Florido del Corral, D. y Menanteau, L.

2006. "Geohistoria de las almadrabas del golfo ibero-marroquí (siglos XVI-XXI)". En Ruiz Mata, D. (Coord.): Historia de la Pesca en el ámbito del Estrecho, II (pp. 855-926). Sevilla: Consejería de Agricultura y Pesca y Consejería de Innovación Ciencia y Empresa.

Florido del Corral, D.

2013. "Las almadrabas andaluzas bajo el consorcio nacional almadrabero (1928-1971): aspectos socio-culturales y políticos". SEMATA, 25: 117-151.

Florido del Corral, D. (Coord)

2017. Las almadrabas suratlánticas andaluzas. Historia, tradición y patrimonio (siglos XVIII-XXI).

Sevilla: Ed. Universidad de Sevilla.

García Henche, B.

2018. "La Ruta Milenaria del Atún: Lecciones aprendidas de un producto turístico experiencial en el litoral gaditano". International Journal of World of Tourism, Vol. 5, $\mathrm{N}^{\circ} 9$.

Guía del Paisaje Cultural de la Ensenada de Bolonia. Avance (2004).

2004. Sevilla: Instituto Andaluz del Patrimonio Histórico. Junta de Andalucía.

Gómez Alzate, A.

2010. "El paisaje como patrimonio cultural, ambiental y productivo. Análisis e intervención para su sostenibilidad". Revista Kepes, 6: 91-106.

Gonzalbes Cravioto, E.

1999. "La pesca del atún en la antigüedad". Aljaranda Revista de Estudios Tarifeños, 34: 16-18.

Huici Goñi, M. P.

1990. "Las Comisiones de Monumentos históricos y artísticos con especial referencia a la Comisión de Navarra”. Príncipe de Viana, 189: 119-210.

Lagóstena Barrios, L.

2001. La producción de salsas y conservas de pescado en la Hispania romana (II a. C-VI d. C). Barcelona:

Universidad de Barcelona.

Liaño Rivera, M.

1997. "La pesca del atún. Salir por la vía de Tarifa". Aljaranda. Revista de Estudios Tarifeños, 26: 4-6. Llul Peñalba, J.

2005. "Evolución del concepto y de la significación social del patrimonio cultural". Arte, Individuo y Sociedad, 17: 175- 204.

Martínez Shaw, C.

2009. "Las almadrabas españolas a fines del Antiguo Régimen". Estudis, 35: 259-286.

Mateu i Lladó, J.

2014. "Los paisajes culturales patrimonio mundial como herramientas de gestión territorial. El caso de la Serra de Tramuntana de Mallorca". Boletín de la Asociación de Geógrafos Españoles, 66: 253-270. Menasche, R.

2011. "Cuando la comida se convierte en patrimonio: puntualizando la discusión". En Mingote Calderón, J.L. (Coord.) Patrimonio inmaterial, museos y sociedad. Balances y perspectivas de futuro. Madrid: Ministerio de Cultura.

Ollero Lobato, F. (Coord.)

2010. Patrimonio cultural, identidad y ciudadanía. Quito: Ed. Abya-Yala.

Orella Unzué, J. L.

2010. "Geohistoria”, Lurralde. Invesigación y Espacio, 33: 233-310. 
Palacios Esteban, I.

2010. Almadrabas del Estrecho y Literatura. Federación Andaluza de Cofradías de Pescadores [ed. digital]. Ponsich, M.

1988. Aceite de oliva y salazones de pescado. Factores geoeconómicos de Bética y Tingitania. Madrid:

Universidad Complutense.

Rivas Medina, L., Frende Mato, E.

2003. "La pesca, factor determinante en la conformación del entorno de Baelo Claudia". PH. Boletín

del Instituto Andaluz del Patrimonio Histórico, 44: 108 -109.

Rodrigo Cámara, J. M. et al.

2012. "Registro de paisajes de interés cultural de Andalucía. Criterios y metodología". PH. Boletín del

Instituto Andaluz del Patrimonio Histórico, 81: 64-75.

Santos García, A.

2010. "El proyecto de La Chanca". Boletín La Laja, 11: 89-98.

Santos García, A.

2007. Patrimonio Cultural Litoral de La Janda Vol. II. Patrimonio de Conil de la Frontera. Ed. GDR Litoral de La Janda.

Sarria Muñoz, A.

1994. "Los privilegios de los duques de Medina Sidonia sobre las almadrabas andaluzas". Aljaranda

Revista de Estudios Tarifeños, 15: 9-11.

Silva Pérez, R., Fernández Salinas, V.

2015. "Claves para el reconocimiento de la dehesa como paisaje cultural de la UNESCO". Anales de Geografía, 35 (2): 121-142.

Soto Melgar, M.

2014. "Estudio onomasiológico y semasiológico de la terminología almadrabera gaditana". En Grande López, C.; Martín Ayzpuru, L.; Salicio Bravo, S. (Coords.) Con una letra joven: avances en el estudio de la Historiografía e Historia de la lengua Española (pp. 281-289.). Salamanca: Ed. Universidad de Salamanca.

Souto, P. (Coord.)

2011. Territorio, lugar, paisaje. Prácticas y conceptos básicos en geografía. Buenos Aires: Ed. Facultad de Filosofía y Letras, Universidad de Buenos Aires.

Zoido Naranjo, F.

2004. "El paisaje. Patrimonio público y recurso para la mejora de la democracia". PH. Boletín del Instituto Andaluz del Patrimonio Histórico, 50: 66-73.

\section{Apéndices}

Consejería de cultura de la Junta de Andalucía

http://www.juntadeandalucia.es/organismos/cultura/areas/bienes-culturales.html

Estrategia de Paisaje de Andalucía. Disponible en: http://www.juntadeandalucia.es/medioambiente/ portal_web/web/temas_ambientales/evaluacion_integracion_planificacion/planificacion_ambiental/ estrategias/estrategia_paisaje/Estrategia_de_Paisaje_de_Andalucia_2012.pdf

El Registro ICCAT de almadrabas de atún rojo del Este contiene la lista de las almadrabas autorizadas por cada CPC para pescar, retener, transferir o desembarcar atún rojo. https://iccat.int/es/Trapsres. asp?cajaFlag=checkbox\&cajaTrap=checkbox\&cajaReg=checkbox\&selectOrder $=1 \&$ selectOrder $2=6 \&$ selectInterval=-1\&Submit=Buscar

Huelvainformación.es, 8.8.2017, «Lepe recuperará la única almadraba de la costa de Huelva». Disponible en: http://www.huelvainformacion.es/provincia/Lepe-recuperara-unica-almadraba-Huelva_0_1161484467.html Plan Nacional del Paisaje Cultural. Texto difundido por el Instituto del Patrimonio Cultural de España. Disponible en: http://ipce.mcu.es/conservacion/planesnacionales/paisajes.html

UNESCO

2006. Textos básicos de la Convención de Patrimonio Mundial de 1972. París, Centro del Patrimonio Mundial de la UNESCO. Disponible en: http://whc.unesco.org/uploads/activities/documents/activity$-562-2 . p d f$ 


\section{R-PICA}

2016. Instituto Andaluz del Patrimonio Histórico. Consejería de Cultura. Disponible en: http://www. iaph.es/paisajecultural/modules.php?name=Downloads\&d_op=viewdownload\&cid=191\&opcionMe $\mathrm{nu}=\mathrm{bOtrosServicios0 \& orderby=title} \mathrm{(consultado} \mathrm{1.2.2017)}$

\section{Notas}

1 Nos referimos a aquellas tipologías de valores culturales de carácter artístico, arquitectónico y, en general, de carácter material.

2 UNESCO determinó que los potenciales paisajes culturales debían cumplir, al menos, uno de los diez criterios que consideró imprescindibles. Actualmente aunque no existe una carta internacional universal y aplicable a los paisajes culturales, sí existen por tanto directrices de UNESCO para ello, y surgen nuevos criterios cada pocos años. Estos bienes culturales o sitios, también llamados mixtos, constituyen desde entonces una nueva categoría del patrimonio mundial y hasta la fecha han sido declarados 35 sitios; dos de ellos en España. Ver http://whc.unesco.org/en/list/?\&type=mixed

3 La cuestión de la escala del bien cultural al tratarse de paisajes culturales es determinante entre otras cuestiones para establecer la norma de aplicación o la institución adecuada para reconocerlo como tal, o para el diseño de un plan de gestión.

4 Las Comunidades Autónomas han ido incorporando el concepto de paisaje a la planificación de sus territorios a través de estrategias (Estrategia de Paisaje de Andalucía, 2012), directrices, atlas, registros de paisajes, etcétera. También legislando al respecto: Reglamento de Ley 5/2014, de 25 de julio, de la Generalitat, de Ordenación del Territorio, Urbanismo y Paisaje de la Comunidad Valenciana; Proyecto de Ley del Paisaje del País Vasco (aprobado en 24.1.2012); Ley 7/2008, de 7 de julio, de Protección del Paisaje de Galicia; Ley 8/2005, de 8 de junio, de protección, gestión y ordenación del paisaje de Cataluña.

5 Asímismo la importancia del agente paisajístico es reconocido en el articulado del Plan de Ordenación del Territorio de Andalucía (2006) y en el de sus Estatutos de Autonomía de 1981 (art. 12.3.6) y 2007 (arts. 28, 33, 37 y 195).

6 También podemos citar el Atlas del Patrimonio Inmaterial de Andalucía (IAPH) herramienta de documentación del IAPH, donde se recoge específicamente la almadraba.

7 Territorio del litoral atlántico andaluz entre los municipios de Barbate y Tarifa, considerado en esta obra diferente del circundante en base a sus valores naturales y culturales.

8 Los grados de patrimonialización pueden ser de distinto tipo. Un registro no conlleva cautelas legales y jurídicas como lo hace la inscripción de un bien, aunque sí reconoce los valores de lo registrado, pone de manifiesto las características de un bien, y finalmente constituye un aval de su existencia.

9 Se trata de distintas prácticas culinarias y formas de preparar atún y túnidos sobre todo en los entornos almadraberos, de hombres trabajadores y trabajadoras que recibían pescado como parte de su pago desde las empresas almadraberas. Son prácticas hoy en peligro por las nuevas dinámicas laborales.

10 Forma en que se trocea canónicamente a los animales para extraer los distintos tipos de carnes que contiene.

11 Una de las huellas más evidente de ese trasiego migratorio histórico al que se ha hecho referencia.

12 La Convención para la salvaguardia del patrimonio cultural inmaterial de 2003 (UNESCO) colocó en el centro de los procesos de salvaguarda del patrimonio a la sociedad civil, a las comunidades, verdaderas depositarias de los bienes o manifestaciones patrimoniales.

$13 \mathrm{https://iccat.int/es/Trapsres.asp?cajaFlag=checkbox \& cajaTrap=checkbox \& cajaReg=checkbox \& selectOrder=1 \& selectOrd}$ er2=6\&selectInterval=-1\&Submit=Buscar (consultado 10.4.2018)

14 Recordemos que un reconocimiento por parte de UNESCO debe estar precedido de la declaración como BIC del bien cultural por el estado donde se encuentre dicho bien

15 Por otro lado, en 2013 el grupo puso en marcha además un proyecto turístico de desarrollo territorial llamado La Ruta Milenaria del Atún. Así mismo ha ubicado 7 monumentos dedicados al atún en municipios donde su vinculación con la pesca almadrabera es especialmente significativa históricamente: Cádiz, Chiclana de la Frontera, Conil de la Frontera, Barbate, Zahara de los Atunes, Tarifa y La Línea de la Concepción -si bien podrían también ubicarse otros en San Fernando y Rota-.

16 Ambas actividades cerradas desde 2012. http://www.andaluciapescadeportiva.es/cierra-el-museo-de-interpretacion-del-atun-de-almadraba-en-barbate/

17 En este sentido son numerosos los autores que alertan del uso destructivo o, al menos desmedido, del patrimonio. Un ejemplo ya clásico de ello es la obra de 2007 de Antonio Ariño Construcción del patrimonio cultural e identidad en la sociedad del riesgo y de la información, donde entre las amenazas y peligros que se ciernen sobre el patrimonio señala su propia destrucción por codicia propia de los tiempos modernos y del progreso mal entendido.

Recibido:

$16 / 05 / 2018$

Reenviado: 